\title{
Discapacidad Y Género: Una Perspectiva de derechos humanos
}

\author{
Flor Deisy Arenas Castro \\ Universidad Pedagógica y Tecnológica de Colombia \\ Doctorado en Ciencias de la Educación
}

\section{Resumen:}

A través de la historia las mujeres con diversidad funcional y/o discapacidad, han sido objeto de estudio desde perspectivas biológicas y la defecto logia, desde lo que le hace falta: es sorda, ciega, con parálisis cerebral, con discapacidad intelectual, autista, con problemas mentales, y así otras tantas denominaciones que solo reflejan la imposibilidad ser mujeres, seres humanos que piensan, sienten y que tienen deseos de realizar un proyecto de vida como cualquier otra mujer de manera autónoma. De esta manera, este proyecto de investigación tiene como objetivo reconstruir las historias de vida de cuatro mujeres del entorno colombiano, con diversidad funcional y/o discapacidad, que presentan un desarrollo de vida personal autónomo, que les permiten participar de los diversos escenarios sociales de acuerdo a sus intereses y posibilidades.Esta investigación de tesis doctoral, busca reconocer y dignificar a estas mujeres a través de sus relatos, historias de vida y dar a conocer a la humanidad, sus deseos, frustraciones y construcciones sociales que les ha permitido constituirse como mujeres, desde la marginación, la segregación y estigmatización de ser mujeres y mujeres con alguna diversidad funcional y/o discapacidad; reconociendo los lugares de enunciación donde han tenido un nivel de incidencia y desarrollo pleno, autónomo, desde lo personal y profesional, superando toda acción de exclusión.

Palabras clave: Género, discapacidad, educación, derechos humanos,

\section{Introducción}

Este trabajo de investigación doctoral, está orientado a reconocer la importancia que tiene la educación en el ejercicio de los derechos humanos de las mujeres con discapacidad del entorno colombiano y que han logrado consolidar un proyecto de vida autónomo, para el ejercicio de sus derechos y deberes como ciudadanas; para ello se toma cuatro historias de vida de mujeres con discapacidad, del territorio colombiano.

Las investigaciones desde la perspectiva de estudios de género, permiten conocer las situaciones que viven habitualmente las identidades de género, es decir, mujeres, hombres y cada uno de los grupos pertenecientes al LGTTBIQ,en escenarios sociales que consolidan prácticas de desigualdad, vulneración de derechos, discriminación contra el goce pleno y disfrute de la vida de las personas. Para el caso de esta investigación de la sistemática invisibilización de las condiciones que viven las mujeres con discapacidad en el territorio colombiano.

Desde esta perspectiva, es importante reconocer que el concepto de género, surge como categoría social y esta permite explicar las desigualdades entre hombres y mujeres. Entonces los discursos de lo femenino y lo masculino se conforman a partir de relaciones culturales, e históricamente se han constituido desde un sistema de poder, desde discursos hegemónicos donde las ideas de un sexo más fuerte, lograron infundir la idea del carácter natural de las mismas. Para precisar, es necesario decir que lo femenino o lo masculino no se refiere al sexo de las personas, sino a las conductas consideradas femeninas o masculinas; de esta manera la categoría de género puede entenderse como una explicación acerca de las formas que adquieren las relaciones entre los géneros.

De esta manera, las mujeres con discapacidad históricamente sido invisibilizadas, tal como lo describe el informe alternativo entregado en el mes de julio del 2016 por CONALIVE, Organización Nacional de Personas con discapacidad visual a las Naciones Unidas, existe una clara y sistemática vulneración de los derechos de las mujeres con discapacidad, al no existir la participación incidente de estas mujeres en el plano del desarrollo de la política pública para el goce efectivo de los derechos de las mujeres. Ello hace necesario analizar a luz de este informe sombra, las recomendaciones y garantizar que las mujeres puedan estar allí, como actoras fundamentales de las transformaciones de sus realidades y las de sus congéneres.

En este informe se deja ver la permanente discriminación y prácticas de segregación, invisibilización hacia las mujeres con discapacidad, que las despoja de la oportunidad de competir en condiciones de igualdad, así como de aprovechar las oportunidades de las que goza cualquier otra mujer y ello indudablemente conlleva a una consecutiva vulneración de los derechos humanos. Situaciones como el acceso a la información que le permita el ejercicio pleno a la participación, en escenarios laborales, políticos, educativos, culturales y recreativos. Es aquí donde recobra importancia esta investigación, pues permite reconfigurar las prácticas a luz del reconocimiento pleno de las mujeres con discapacidad, como actoras de las transformaciones sociales, culturales y políticas de la sociedad colombiana. 
En el ejercicio metodológico la investigación se divide en tres capítulos: en el primero se encuentra la contextualización y formulación del problema de investigación, la justificación, y los objetivos; en el segundo, el marco referencial donde se puede encontrar las orientaciones teóricas y conceptuales que dan orientaciones epistemológicas de la investigación y el tercer capítulo el marco metodológico, que da rigor investigativo.

Históricamente la sociedad ha tendido la tendencia de aislar y segregar a todas aquellas personas y procesos culturales que resultan extraños a la cultura dominante, a todo lo que la sociedad ha denominado "normal" y lo denomina "anormal", y las mujeres con discapacidad no han sido ajenas a estas acciones. Colombia ha tenido importantes avances los últimos 21 años en pro de reconocer la pluridiversidad de nuestra región y por lo tanto de sus habitantes; sin embargo, las mujeres con discapacidad carecen de apoyos o dispositivos legales eficaces y eficientes para eliminar estas conductas discriminatorias.

Las mujeres con discapacidad se enfrentan permanentemente a situaciones de exclusión como:

- Falta de oportunidades para el ingreso a escenarios educativos que contemplen los estilos y ritmos de aprendizaje de las mujeres de acuerdo a su condición diversa.

- Falta de oportunidades laborales y salarios justos.

- Menor acceso a servicios de salud

- Falta de programas y servicios dirigidos para las mujeres

- Victimas de todo tipo de violencias

Este proceso se encrudece, cuando existe un marco normativo, algunas políticas públicas y representaciones sociales que fomentan la dependencia; de igual manera las mujeres con discapacidad llevan una mayor carga que los hombres con discapacidad, por la persistencia de prejuicios, estereotipos e ideas en todos los ámbitos que distorsionan la imagen social y la percepción de las mujeres con características distintas a los de los hombres con discapacidad, es decir, se habla de discapacidad como una condición homogenizante, sin distinguir a los hombres y las mujeres.

La inclusión supone un reto más grande, no sólo supone la equiparación de goce efectivo de derechos y participación incidente, debe generar acciones para lograr la equiparación en cuanto a género, y para alcanzar estas metas se debe tener un mejor conocimiento de las realidades de las personas con discapacidad y de las mujeres y de esta manera no fomentar la consolidación de un grupo social aislado e invisible, que se enfrenta a todo tipo de restricciones y limitaciones, sometidas a tratos denigrantes y desiguales que atentan contra la autonomía y la libertad de desarrollo.

Históricamente las mujeres con discapacidad han estado sometidas a una serie de prácticas discrinatorias como:

- La permanente idea de la infantilización de las mujeres, crearlas eternas niñas, que requieren de una especial protección.

- La tendencia a tratarlas bajo una especial protección.

- La creencia de considerarlas mujeres asexuadas.

- Se les quita la posibilidad de decidir si desean ser madres. Inclusive con prácticas de esterilización forzada.

- La creencia que las mujeres solo pueden desempeñar labores domésticas.

La existencia continua de discriminaciones y prejuicios injustos e injustificados hacia las mujeres con discapacidad, que se traducen en: violencias de género, sexuales, a ser reconocidas como mujeres, a tener oportunidades a un desarrollo de un proyecto de vida, hacen que se presenten representaciones sociales, que despoja a las mujeres de la oportunidad de competir en condiciones de equidad, así como de aprovechar las oportunidades de las que goza cualquier otra mujer y ello indudablemente conlleva a una consecutiva vulneración de los derechos humanos. De acuerdo a ello, se formula como pregunta que orienta esta investigación la siguiente.

A través de la historia las mujeres con diversidad funcional y/o discapacidad, han sido objeto de estudio desde perspectivas biológicas y la defectologia, desde lo que le hace falta: es sorda, ciega, con parálisis cerebral, con discapacidad intelectual, autista, con problemas mentales, y así otras tantas denominaciones que solo reflejan la imposibilidad ser mujeres, seres humanos que piensan, sienten y que tienen deseos de realizar sus propios planes de vida como cualquier otra persona de forma independiente. De esta manera, este proyecto de investigación tiene como objetivo desde la perspectiva de estudios de género, reconocer en las historias de vida de cuatro mujeres con diversidad funcional y/o discapacidad del entorno colombiano, las representaciones y prácticas sociales que les han permitido tener un desarrollo personal autónomo y participar plenamente en diversos escenarios sociales de acuerdo a sus intereses y posibilidades. 
Al analizar la literatura de estudios en discapacidad, se habla de un término que pretende ser universal, y se usa indistintamente para hablar de los hombres y de las mujeres, pero no se hace diferencia de relaciones que se tejen alrededor de cada uno de los dos géneros, así que las mujeres con discapacidad han sido explicadas desde las ciencias de la medicina, la sociología, la educación y desde las particularidades del género dominante, es decir los hombres con alguna condición particular de vida de discapacidad.

De esta manera, es necesario reconocer y dignificar a estas mujeres a través de sus relatos, historias de vida y dar a conocer, sus deseos, luchas y construcciones sociales, que les han permitido tener desde sus lugares de enunciación niveles de incidencia y desarrollo pleno personal y profesional, y este es el objetivo de esta investigación, donde permite analizar cuáles son esas posibilidades de desarrollo de estas mujeres en contextos familiares, escolares y sociales que permitieron ser mujeres con proyectos de vida autónomos.

Así, esta investigación permite hacer visibles las voces de mujeres que desde la marginación y la estigmatización han logrado un proyecto de vida autónomo, desde lo personal y profesional, superando acciones de exclusión y a partir de allí, aportar a la reconfiguración de una sociedad colombiana, que requiere avanzar en el reconocimiento de la diferencia como característica propia las identidades culturales.

Es necesario reconocer la estigmatización a la que han sido sometidas las mujeres con discapacidad, siendo vistas como mujeres de especial protección, una raza inferior a la cual la sociedad le debe negar la posibilidad de ser mujeres plenas, que piensen en el desarrollo de procesos tan sencillos para cualquier otra mujer como: formarse académicamente, trabajar, tener relacione sexuales, casarse, tener hijos, y es precisamente el enfoque de género, que permite reconocer en esta investigación una manera de deconstruir saberes y prácticas arraigadas en la sociedad colombiana.

En este sentido, la perspectiva de estudios de género permite interpretar la realidad y de intervenir en ella, entendiendo que el sexismo y el poder patriarcal se torna visible en las problemáticas sociales y más en las que viven las mujeres con alguna discapacidad.

\section{Marco Conceptual}

Para dar fundamento teórico, epistemológico, metodológico a esta investigación y de acuerdo al objetivo planteado, el cual está orientado a establecer las representaciones sociales, desde una perspectiva de estudios de género, de las mujeres con discapacidad en Colombia, que han logrado construir un proyecto de vida autónomo para el ejercicio de sus derechos como ciudadanas. Para ello se realiza revisión del marco de antecedentes, y se desarrollan conceptos como: representaciones sociales, género, discapacidad y autonomía. A continuación, se presenta

De acuerdo al objetivo de esta investigación, la construcción del estado del arte se realiza en fuentes de información como: bases de datos, tesis del Doctorado de RUDECOLOMBIA, bibliotecas, grupos de investigaciones de universidades En dos categorías: género y discapacidad. La indagación se realiza en un periodo de tiempo de ocho años 2009-2016, teniendo en cuenta que fue en el año 2009, cuando el Estado Colombiano aprobó el Tratado Internacional de los derechos humanos de las personas con discapacidad, de las Naciones Unidas con el objetivo de proteger y promover los derechos humanos de más de los 650 millones de personas, que son alrededor del $10 \%$ de la población mundial, y la cual carece de oportunidades en equiparación de oportunidades como el común de las personas.

Estos derechos fundamentales se pueden resumir es seis, los cuales son:

- Derecho a recibir una educación de calidad y pertinente.

- Derecho a conseguir un empleo digno y bien remunerado y en condiciones de equidad.

- Derecho a acceder a la información.

- Derecho a acceder a servicios de salud y rehabilitación.

- Derecho a movilizarse y desplazarse por todos los escenarios.

- Derecho a tener participación incidente.

De esta manera a continuación se presentan los hallazgos encontrados alrededor del objeto de estudio que contribuyen a dar soporte teórico y metodológico. El primer documento que se aborda es la denominada “Autoconcepto de estudiantes con discapacidad”realizada por María Tamara Polo Sánchez y María Dolores López, docentes del Departamento de Psicología Evolutiva, de la Facultad de Ciencias de la Universidad de Granada, se publica a través de artículo en la Revista Latinoamericana de Psicología en el año 2011.

El objetivo fue identificar el autoconcepto de mujeres estudiantes con discapacidad: visual, auditiva y motora frente a otras mujeres sin discapacidad, y explorar las diferencias existes entre los dos grupos de mujeres. Participaron 102 estudiantes 51 con discapacidad y 51 sin ella, pertenecientes a diferentes carreras de la Universidad de Granada, España. 
En la investigación se puedo identificar que las mujeres estudiantes con discapacidad tienen mayores dificultades que la población en general pues, además de su propia condición, deben superar barreras arquitectónicas y psicosociales que realmente afectan el desarrollo pleno de las personas. El trabajo sustenta teóricamente el concepto de discapacidad, desde la Organización Mundial de la Salud, entidad que determina que la discapacidad, es el resultado de la interacción de la persona que presenta una deficiencia ante las barreras físicas y actitudinales existentes en su entorno; y es estas actitudes negativas y prejuicios son los que imposibilitan la plena participación. Las investigadoras identificaron que el concepto del yo, de las mujeres con discapacidad se desarrolla del mismo modo que el de las mujeres sin discapacidad, pero las influencias negativas como el rechazo, la discriminación, las relaciones interpersonales a las que se enfrentan desde la infancia terminan por afectar el desarrollo del autoconcepto de las personas. Los resultados de este trabajo son valiosos, en tanto resalta que "las mujeres suelen tener mayor probabilidad que los hombres de experimentar problemas emocionales, como la ansiedad y la depresión, y que estos surgen en la adolescencia” (Tamara, López, 2011, p. 5). Como consecuencia de la discriminación a la que son sometidas por los distintos entornos.

El segundo documento abordado, tiene como objetivo mostrar la importancia de incorporar la perspectiva de género en los procesos de intervención que realizan los profesionales de trabajo social con las personas con discapacidad intelectual que están en los centros residenciales y de día en Andalucía, España. Esta investigación concluyo que "los discursos de las y los profesionales sitúan a la perspectiva de género lejana de los centros, aunque muestra la discriminación de la profesión desde el trasvase de modelos de cuidado patriarcal a la intervención" (Díaz, 2013, p. 1).

La autora Rosa Díaz, logró identificar que existen diferencias en el trato hacia las mujeres con discapacidad intelectual, y ello se debe a los roles que desempeñan las mujeres como consecuencia de la influencia negativa de las familias que obstaculizan la participación de ellas en diversos contextos. Una de las principales premisa de la investigación estuvieron centrados en identificar que desde el "Trabajo Social se ha definido que las personas con discapacidad tienen dificultades para vivir una vida Plena, productiva, con independencia, en una sociedad cargada de estigma y discriminación y con unas políticas y prácticas que las han considerado no aptas para la sociedad, enfermas, funcionalmente limitadas" (Díaz, 2013, p. 4).

Esta postura teórica frente a los sujetos, hace que se reafirmen no solo prácticas negativas, sino que se perpetúen tratos marginales y estigmatizaste frente a las mujeres con discapacidad.

Tal como lo afirma la autora, las mujeres con discapacidad intelectual, han sufrido de situaciones que las invisibilizan, lo que repercute en la consolidación de identidades y prácticas que reconozcan en la diferencia de las mujeres las posibilidades de consolidar prácticas de equiparación de derechos. Y es precisamente el restablecimiento de los derechos de las mujeres con discapacidad en temas como la maternidad, a no ser esterilizadas que toman un papel trascendental al interior de las investigaciones realizadas por la disciplina de trabajo social.

Con ello se busca sentar posiciones críticas frente a los discursos como los derechos humanos y permitir que las mujeres con discapacidad puedan construir un proyecto de vida con autonomía y libre determinación. En este aspecto es necesario analizar los pronunciamientos del marco legislativo de nuestro país, que les permite a las familias tomar decisiones de esterilizar a las mujeres con discapacidad por parte de sus familias.

La metodología usada fue entrevistas a profundidad y permitió establecer categorías conceptuales que consintieron ordenar los discursos, resaltando que la discriminación hacia las mujeres no solo se verbaliza, sino que seobjetiviza en las practicas. "Por desconocimiento, por machismo, nos han llamado "(...)", "asistontas". Nuestra profesión es básicamente femenina, hay muy pocos hombres y esto ha influido, claro, ahí hay mucho de despecho machista y el desprecio hacia el género femenino que se refleja en la forma de ver a la profesión” (Díaz, 2013, p.8). Esta afirmación demuestra las diferencias de trato de las y los profesionales y sus procesos de intervención frente a los hombres y las mujeres con discapacidad.

El análisis de la información estadística establece que existen un mayor número de hombres atendidos que mujeres; y tal como lo afirma la autora el "ser mujer incide en la intervención y en el trato que se ofrece en los centros residenciales y de día para personas con discapacidad intelectual en Andalucía y será necesario desarrollar estrategias que garanticen la igualdad de oportunidades entre hombres y mujeres tanto para la práctica profesional como para la interacción con ciudadanos y ciudadanas en estos dispositivos.”(Díaz, 2013, p.10). Esto es importante, dado que si bien los discursos de la disciplina resaltan la importancia de la equidad de género las prácticas demuestran acciones distintas.

\section{Representaciones Sociales}


La teoría de las representaciones sociales, permite sin duda alguna analizar las subjetividades individuales y sociales que se dan producto de las relaciones humanas en diversos contextos culturales; para el caso de esta investigación se busca establecer las representaciones sociales que se construyen alrededor de las mujeres con discapacidad, que han logrado consolidar un proyecto de vida autónomo, desde lo personal y profesional, superando acciones de exclusión, discriminación.

Al realizar el rastreo del concepto, se puede determinar que 1898, el sociólogo Durkheim, propuso la teoría de Representación Colectiva, la cual analizaba las relaciones que se presentan entre los seres humanos y los objetos y como estos los afectan, es decir, son mecanismos explicativos acerca de las ideas y las creencias; afirmaba que Los hechos sociales no difieren sólo en calidad de los hechos psíquicos; tienen otro sustrato, no evolucionan en el mismo medio ni dependen de las mismas condiciones. Esto no significa que no sean también psíquicos de alguna manera, ya que todos consisten en formas de pensar o actuar. Pero los estados de la conciencia colectiva son de naturaleza distinta que los estados de conciencia individual; son representaciones de otro tipo: tienen sus leyes propias. (Durkheim, 1898, p. 273)

Entonces, las representaciones colectivas, son concebidas como formas de conciencia que la sociedad asigna a los sujetos, ello significa entonces que este concepto tiene una carga de poder restrictivo sobre los miembros de una sociedad. Por su parte para SergeMoscovici, las representaciones sociales son construcciones generadas en los procesos de interacción social, partiendo de las realidades que viven las comunidades; entonces las representaciones sociales se deben definir como una producción y una elaboración de carácter social. La teoría de Durkheim, se convirtió en el punto de partida para que Moscovici formulará su postura conceptual y en este desarrollo plantean tres tipos de representaciones sociales:

Representaciones hegemónicas: son aquellas que son reconocidas por todos los miembros de una comunidad.

Representaciones emancipadas: estas sin bien no tienen un carácter hegemónico en las comunidades, si emergenentre subgrupos específicos, que por lo general constituyen nuevas formas de pensamiento social. Representaciones polémicas: estas emergen en grupos que atraviesan por situaciones de conflicto o controversia social, respecto a hechos u objetos sociales relevantes y ante los cuales expresan formas de pensamiento divergentes.

Entonces la teoría de las representaciones sociales, orientan dos procesos en las practicas, la primera sirven para orientar y guiar la acción y la segunda justifica los conocimientos y las prácticas; significa que las personas actúan de acuerdo con sus representaciones pero estas cambian en teniendo criterios como comportamientos y prácticas. Por ello las “

Representaciones Sociales constituyen una formación subjetiva multifacética y polimorfa, donde fenómenos de la cultura, la ideología y la pertenencia socio estructural dejan su impronta; al mismo tiempo que elementos afectivos, cognitivos, simbólicos y valorativos participan en su constitución. (Perera, 2006, p. 8.)

Por su parte Denise Jodelet en 1986, retoma los principios de Moscovici, plantea que las representaciones sociales son una forma de conocimiento específica, que designan los pensamientos sociales, que están mediados por situaciones como: los acontecimientos de la vida diaria, las características de nuestro medio ambiente y las informaciones que en él circulan, las personas de los diversos entornos con las que se interactúa; para Jodelet el conocimiento se construye y elabora socialmente a partir de las experiencias y de las informaciones y modelos de pensamiento que recibimos y transmitimos a través de la tradición, la educación y la comunicación social. Entonces son los procesos que los seres humanos construyen a partir de las realidades y con ellas buscan comprender y explicar el mundo.

De acuerdo a la naturaleza de esta investigación, que está orientada a conocer las representaciones sociales alrededor de las mujeres con discapacidad en Colombia, se sustenta desde los planteamientos de Moscovici quien teoriza "es un corpus organizado de conocimientos y una de las actividades psíquicas a las cuales los seres humanos hacen inteligle la realidad física y social, se integran a un grupo o relación cotidiana de intercambios, liberan los poderes de su imaginación"(Moscovici, 1979 p. 17)

Entonces se puede inferir que las representaciones sociales son sistemas cognoscitivos con una lógica, lenguajes propios, y no representan simplemente opiniones o actitudes frente a algo, sino permiten organizar las realidades sociales y culturales, sin embargo, para el caso de las mujeres con discapacidad, que se enfrentan a una doble discriminación por ser mujeres y mujeres con discapacidad, requieren que la sociedad transforme estas representaciones a partir del reconocimiento de la diferencia y la diversidad como elementos constitutivos de la humanidad.

En este punto es necesario pensar entonces las tres condiciones que permiten que emerjan las representaciones sociales:

1. Dispersión de la información: esta se refiere a la cantidad y calidad de la información frente a un tema y ello se debe a la multiplicidad de fuentes de información que pueden obtener y la vinculación que se puede realizar por categorías. 
2. Focalización: este proceso implica las interacciones sociales que ocurren en una colectividad y que conllevan a la elaboración de juicios y opiniones.

3. Presión a inferencia: se presenta cuando un grupo de personas o una comunidad reclama acciones focalizadas en temas que son de interés público.

\section{Género.}

El segundo concepto a desarrollar, de acuerdo al propósito investigativo es el de género, el cual las epistemologías feministas han logrado consolidar como:

Un campo de diferencia estructurada y estructurante, donde los tonos de extrema localización, del cuerpo íntimamente personal e individualizado, vibran en el mismo campo con emisiones globales de alta tensión" la encarnación feminista, por lo tanto, no trata de localizarse fija en cuerpo redificado, femenino o de otra manera, sino de nudos en campos, inflexiones y orientaciones y de responsabilidad por la diferencia en campos de materialsemióticos de significados. (Haraway Donna, 1991 p. 334)

Es decir, que las epistemologías feministas han logran consolidar campos de conocimientos acerca de las realidades de las mujeres, de sus luchas y visibilizar sus historias y voces, desde cada uno de sus lugares de enunciación. Tal como lo plantea Haraway Donna (2011), la perspectiva de género "ha surgido como herramienta teórica y metodológica que permite plantear una crítica a las áreas de conocimiento tradicionales, mostrando la necesidad de una mayor profundidad en el examen de los conceptos y supuestos que todavía existen en los distintos campos del saber". (Haraway Donna, 1991 p. 11).

Entonces, lo que buscamos las mujeres simplemente es ser reconocidas por la diversidad que configura el ser mujer; Haraway Donna dice que las "Feministas no necesitan una doctrina de la objetividad que prometa trascendencia, una historia pierda la puesta de sus mediaciones en donde alguien pueda ser considerado responsable de algo, ni un poder instrumental ilimitado.

No queremos una teoría de poderes inocentes para representar el mundo, en la que el lenguaje y los cuerpos vivan el éxtasis de la simbiosis orgánica. Tampoco queremos teorizar el mundo y mucho menos, actuar sobre él en términos de Sistema Global, pero necesitamos un circuito universal de conexiones, incluyendo la habilidad parcial para traducir los conocimientos entre comunidades muy diferentes y diferencias a través del poder. Necesitamos el poder de las teorías críticas modernas sobre como son creados los significados y los cuerpos, no son para negar los significados y en cuerpos que tengan una oportunidad en el futuro". (p. 322).

Por lo tanto, las mujeres con discapacidad, requieren ser reconocidas como mujeres, con singularidades propias de la diversidad humana, requieren doctrinas que favorezcan la deconstrucción de representaciones sociales alrededor de ellas, y transformar el conocimiento frente a ellas, que les permita ser mujeres y disfrutar de la vida como cualquier mujer, con las capacidades, habilidades e intereses que las caractericen.

Es clara la desigualdad existente entre las mujeres y las mujeres con discapacidad, pues ellas viven una doble discriminación, son despojadas de toda posibilidad de ser libres, autónomas y vivir plenamente sin que sean señalas por su condición de vida, por ejemplo el Estado colombiano legisla sobre procesos como la decisión de ser madres, las universidades se reservan el derecho de admisión a sus programas y cuando egresan las posibilidades de acceder a un trabajo digno y en igualdad de condiciones, queda supeditado al interés personal del empresario o de la entidad o al buen corazón del dirigente de turno; pero jamás por las capacidades de las mujeres, es decir que las mujeres con discapacidad deben dejar de ser objeto de estudio como patología, y ser reconocidas como mujeres con potencialidades y necesidades como todos los seres humanos, indistintamente del género.

Entonces y tal como lo plantea Norma Blázquez Graf en el año 2011, "Las ciencias se han distorsionado con supuestos sexistas en sus observaciones, aproximaciones metodológicas, conceptos y teorías. La teoría critica feminista, muestra que, por ello, el conocimiento científico, no siempre es objetivo, neutral o Universal" (p.111). Ello hace que sea necesario incluir dentro de la teoría critica feminista, a las mujeres con discapacidad, y de esta manera se convierta en una discusión epistemológica, abierta y de cara al reconocimiento de la diferencia de las mujeres, más allá de las mujeres negras, campesinas y las que han sufrido violencia; una discusión abierta amplia donde la influencia de las construcciones culturales son recocidas como valor propio de la singularidad de la humanidad.

\section{Discursos de las personas con discapacidad.}

Cuando somos sensibles, cuando nuestros poros no están cubiertos de las implacables capas, la cercanía de la presencia humana nos sacude, nos alimenta, comprendemos que es el otro el que siemprenos salva. Y si hemos llegado a la edad que tenemos es porque otros nos han ido salvando la vida, insensatamente. 
A los años que tengo hoy, puedo decir, dolorosamente, que toda vez que noshemos perdidoen unencuentro humanoalgo quedó atrofiado en nosotros, o quebrado. Muchas veces somos incapaces de un genuino encuentro porque solo reconocemos a los otros en la medida que define nuestro ser y nuestro modo de sentir, o que no son propicios a nuestros proyectos. Uno no puede detenerse en un encuentro porque está atestado de trabajo, de trámites, de ambiciones. (Ernesto Sábato, 2000, p. 36).

Históricamente el ser humano ha buscado nombrar, denominar, señalar etiquetar, caracterizar: los objetos, sucesos, fenómenos, a las personas por sus construcciones culturales, características de vida, género, raza, que están presentes en las construcciones sociales. Para el caso de las mujeres con discapacidad, ellas no han sido ajenas a este proceso, y se les ha denominado como: anormales, minusválidas, discapacitadas, personas con necesidades educativas especiales, personas en condición de discapacidad, personas en situación de discapacidad, personas diversamente hábiles, personas con barreras para el aprendizaje y la participación social.

Gilda Aguilar Montoya (2004 p. 4), expone tres modelos de atención a las personas con discapacidad: el tradicional, rehabilitador y el de autonomía personal, y cada uno de estos, se encuentran inmersos en las corrientes económicas, políticas y de organizaciones sociales presentes en las comunidades. De esta manera a continuación se describen las prácticas de cada uno de estos modelos.

El primer modelo, el tradicional, pasa por miradas del sujeto como aquel que no debe existir por ser débil, sujeto endemoniado que debe ser sometidos a exorcismo y llevarlo a la hoguera, sujeto que debe ser recluido en instituciones y vivir de la caridad, y el sujeto que requiere de una atención especializada y que debe ser objeto de análisis.

Este último enfoque del modelo tradicional, sin duda alguna abre las posibilidades de iniciar a conocer la fenomenología del ser humano, de la persona con discapacidad, sin embargo, fueron prácticas que llevaron a la segregación y la discriminación por diversas acciones. Aguilar enuncia tres procesos fundamentales

- Lo arraigado de las actitudes negativas hacia la discapacidad.

- El uso y abuso de la psicometría.

- La alarma eugenésica que al extenderse a las ciencias políticas y sociales proporcionó una visión de las personas con retraso mental, como sujetos que destruirían el vigor de la especie humana, al considerarlos inferiores.

La aparición de la construcción de instituciones especializadas, para aquellos sujetos que no tenían la capacidad de adaptarse a los ambientes educativos tradicionales abre el enfoque de atención llamado educación especial desde una concepción médico-educativa, lo que determina prácticas de segregación, y tal como lo describe la autora, Se pueden observar los elementos comunes al modelo tradicional: la marginación, la discriminación, la dependencia y la subestimación de las personas con discapacidad, quienes no son considerados como sujetos con iguales derechos que el resto de las personas que componen la sociedad. (Aguilar, 2004, p. 6)

El segundo modelo el rehabilitador, en el cual presentaron avances importantes frente a las concepciones del sujeto con discapacidad, transformando conceptos como deficiente, inadaptado, minusválido, discapacitado, transformándola por un sujeto que en su singularidad presenta una necesidad educativa especial, pero esta necesidad se analiza desde la heterogeneidad compleja del ser humano; "Desde esta perspectiva el objeto de la educación especial se relaciona con una situación de aprendizaje y no a una condición definida por la naturaleza del "desorden" que mediante la evaluación solo conduce al etiquetamiento, la categorización y la segregación. (Aguilar, 2004, p. 17)

En concordancia con lo anterior, Ainscow (2001), define las necesidades educativas especiales como un proceso de carácter educativo, pues las y los escolares pueden experimentar en cualquier momento de la vida, dificultades sean estas de carácter temporal o permanente, para acceder al currículo; ello lleva a pensar que las causas que inciden por las características del entorno y no solo del sujeto, por lo tanto las instituciones deben realizar ajustes y definir apoyos pedagógicos específicos a que haya lugar, de acuerdo a las necesidades particulares del escolar. Pese a que este paradigma de atención, se considera como uno de los grandes avances en el siglo XX, no cabe duda que presenta dificultades frente a la comprensión del sujeto desde una perspectiva socio antropológica, en tanto que el escolar es quién debe adaptarse al contexto y a currículos y propuestas educativas inflexibles que solo tienden a la "normalización".

El tercer modelo que menciona Aguilar, es el denominado el modelo de la autonomía personal, que cimienta sus principios en el movimiento de vida independiente, el cual lo define Aguilar Una filosofía y además como un movimiento de personas con discapacidades, que trabaja por la igualdad de oportunidades, el respeto a sí mismo y la autodeterminación. Vida Independiente no significa que no necesitemos o que queramos vivir aislados. Vida Independiente significa que queremos el mismo control y las mismas oportunidades de vida diaria que nuestros hermanos y hermanas, vecinos y amigos que no tienen discapacidades. Queremos crecer con nuestras familias, ir a la escuela que escojamos, usar cualquier autobús, tener trabajos acordes con nuestra educación y nuestras capacidades. Más importante aún, necesitamos estar a cargo de nuestras propias vidas, hablar y pensar por nosotros mismos. (Aguilar, p. 22) 
Esta postura invita a generar profundos cambios en la sociedad, donde acciones como la desigualdad, la injusticia social, la discriminación y la marginación a las que son sometidas las personas con discapacidad, se transforma y se piensa en la diversidad humana, en lo extraño del otro, como una posibilidad de construir maneras distintas de vivir y construir las realidades sociales.

Por su parte, (Yarza, Rodríguez, 2007 p. 29), establecen que a comienzos del siglo XX surge en occidente una nueva figura: "la infancia anormal. Con la anormalidad infantil, se posibilita la creación de nuevas instituciones, de sujetos de saber, de prácticas y nociones, unas modificaciones en los discursos pedagógicos, políticos, económicos, etc., y la instauración de un conjunto de instrumentos o técnicas positivas".

Esta mirada permite ver como el surgimiento de la escuela, como institución, hizo que se realizara una clasificación de los sujetos, demarcando este modelo europeo las prácticas que aún persisten en nuestros entorno. Por su parte en el siglo XXI, se han hecho importantes construcciones frente a la comprensión de la discapacidad, avanzando hacía el modelo social, el cual descentra al sujeto como aquel que tiene el problema, y centra su mirada en el contexto como aquel limita la participación de las personas. Desde esta perspectiva, las acciones se dirigen a transformar todos aquellos escenarios sociales. A continuación se enuncia las principales características de este modelo

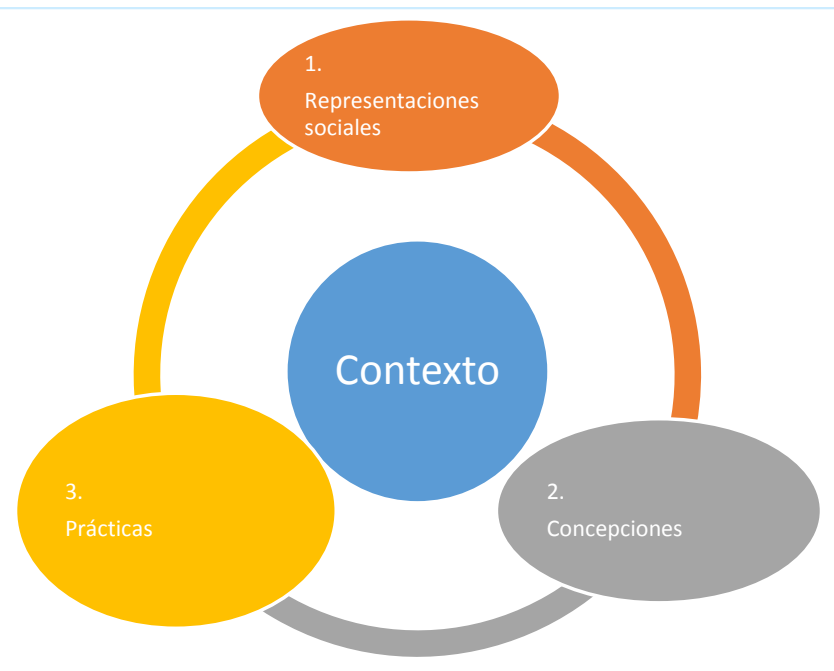

Figura 5. Modelo social de la discapacidad. (Arenas, 2008).

Lo primero que hay que resaltar es la mirada hacía el sujeto, pues este es una persona con pleno uso de derechos y deberes, una persona que puede participar desde sus intereses, posibilidades y habilidades en los procesos sociales, culturales, educativos, políticos, económicos, laborales que desee. Un sujeto con que tiene plenas capacidades para liderar y transformar sus realidades y de quienes lo rodean.

Así se deja la construcción de representaciones sociales alrededor del sujeto, como aquel que esta despojado de toda posibilidad de generar un pensamiento de autonomía e independencia, creando concepciones de un sujeto autoderteminado, lo que conlleva a transformar las prácticas sociales, donde las personas con discapacidad y en especial que las mujeres gozan de derechos en tanto otro (madre, cuidadoras, padres y cuidadores) se los posibilitan.

No obstante este modelo ha tenido una crítica fuerte, en tanto en ocasiones se invisibilizan las condiciones de vida y los apoyos que requieren, es decir, si bien la persona con discapacidad puede tomar decisiones sobre su vida, requiere que el contexto le posibilite ciertos apoyos y que sistemas como el educativo, el de salud y el laboral generen transformaciones al interior la prestación de los servicios que le posibiliten a las mujeres con discapacidad su plena participación.

\section{Autonomía.}

Para el desarrollo del concepto de autonomía es fundamental retomar los principios filosóficos de Kant, si bien él niega las posibilidades de desarrollo de la autonomía de las mujeres, es necesario esbozar el pensamiento que permita realizar algunas precisiones sobre este concepto fundante de esta investigación. Para Kant, la autonomía es una condición sin ecuánime de la dignidad de la naturaleza humana, afirma que la es la voluntad humana aquella que se auto-legisla, es decir que esta no se somete a una ley exterior, sino que está en capacidad de darse a sí misma la ley moral; y es la razón la que es capaz de auto legislarse y no depende de ningún tipo de proceso, por el contrario, este es independiente de cualquier resorte como fundamento subjetivo. 
Entonces, la autonomía surge como un proceso racional del ser humano y esta intrínsecamente relacionada con la voluntad; ello quiere decir que nunca se debe instrumentalizar a la persona en sí misma, ni ella debe instrumentalizar a otros para conseguir determinados propósitos. Es claro que el ser humano posee su voluntad auto-legisladora, es decir, voluntad autónoma, puesto que está en capacidad de darse su propia ley moral.

La autonomía entonces, constituye el principio supremo que posibilita auténticas acciones morales y está estrechamente relacionada con la libertad y esta última es la que permite comprender qué significaría entonces el actuar de manera autónoma; Kant, considera a la libertad como la característica esencial de la voluntad autónoma, entonces la voluntad libre es aquella que se considera a sí misma autora de sus principios de acción, los cuales se encuentran en total independencia de situaciones externas, de intereses particulares que motivan su actuar.

\section{Conclusiones}

Para el caso de esta investigación, si bien es necesario retomar los postulados de Kant, frente al concepto de autonomía, es necesario señalar que a lo largo de sus producciones se puede evidenciar la tendencia a desconocer la posibilidad de las mujeres como seres con el valor de autonomía y la autodeterminación para pensar y actuar, Kant le atribuye condiciones de belleza y humildad a las mujeres y a los hombres la capacidad del razonamiento sobre principios morales. Tal como lo plantea Celina de Jesús Trimiño Velásquez, en su tesis doctorales Aportaciones del feminismo liberal al desarrollo de los derechos de las mujeres señala que "Kant concibe a la mujer como un ser más sensible que racional" y continua señalando que "resalta virtudes que considera les son propias, tales como la limpieza, el pudor y la modestia, ligadas a los roles reproductivos y a lo que se consideraba el deber ser femenino (P.40)

En el estudio de perspectivas de género, la autonomía, representa un valor fundamental como lo es igualdad, la libertad, la solidaridad y se convierte en una categoría ciudadana. Frente a ello tal como lo señala Angélica Bernal Olarte (2010), "Existe una extensa producción académica que ha mostrado como otros valores se han construido como como parte de un proyecto político patriarcal profundamente clasista, racista y heteroxual" (11). Y tal como lo señala esta autora, es el caso específico de Kant, que si bien desarrollo epistemológicamente el

\section{Referentes bibliográficos}

Autoconcepto de estudiantes con discapacidad (2012). Revista Latinoamericana de Psicología, Volumen 44 No 2 , p. 87-98 ISSN 0120-0534

Amezcua, J. A. \& Pichardo, M. C. (2000). Diferencias de género en Autoconcepto en sujetos adolescentes. Anales de Psicología, 16(2), 207-214.

Balandier, (1988). El desorden. Teoría del caos en las ciencias sociales, Barcelona, Gedissa.

Bilbao, M. C. (2008). La integración de personas con discapacidad en la educación superior: percepciones y demandas de docentes y estudiantes de la Universidad de Burgos. Tesis doctoral (inédita): Burgos.

Denzin y Lincoln, (2012). El campo de la investigación cualitativa. España: Editores: Gedisa

Sábato Ernesto (2000., La resistencia. Barcelona: Editorial Seix Barral. S.A.

HernándezSampieri Roberto \&Fernández Collado Carlos \& Baptista Lucio Pilar. (1992). Metodología de la investigación. México: McGRAW-ILL interamericana de editores, S.A. de C. V.

EarlBabbie. (1999). Fundamentos de la investigación social. International Thomson Editores, S.A.

Durkheim, (1898, p. 273). Las reglas del método sociológico. México: Fondo de Cultura Económica,

Pujadas Muñoz Juan José, (2002). El método biográfico: El uso de las historias de vida en ciencias sociales. Madrid: Centro de investigaciones sociológicas.

Kant, (1999). Fundamentación de la Metafísica de las Costumbres. Barcelona: Edición Bilingüe.

Trimiño VelásquezCelina de Jesús, (2010). Aportaciones del feminismo liberal al desarrollo de los derechos de las mujeres. Universidad Carlos Tercero. Instituto de Derechos humanos "Bartolomé de las Casas".

Yarza y Rodríguez (2007). Educación y pedagogía de la infancia anormal. 1870-1940. cooperativa editorial Magisterio. 